\title{
Anterograde Reconstruction of Severe Bi-Canalicular Obstruction with Autogenous Saphenous Vein Graft: A Novel Surgical Technique
}

\author{
Teyyeb Azeem Janjua and Bushra Akbar
}

\begin{abstract}
Severe lacrimal canalicular obstruction mandates a bypass surgery of conjunctivo dacryocystorhinostomy with Lester Jones tube or alternatively retrograde intubation and pseudopunctum generation with conventional, dacryocystorhinostomy (DCR). However, in each case, the natural pathway is violated and added commitment of Lester Jones tube maintenance often leads to patient dissatisfaction. This novel surgical technique aims at de novo, anterograde, reconstruction of lacrimal canaliculi and rehabilitation of the natural lacrimal passage with interposition of autogenous saphenous vein graft. This method offered promising long-term results of functional success in terms of alleviation of epiphora, excellent cosmesis, and an optimal patient satisfaction.
\end{abstract}

Key Words: Severe canalicular obstruction, Autogenous saphenous vein graft, Anterograde reconstruction.

\section{INTRODUCTION}

Severe mid- and distal-canalicular obstructions merit a standard treatment of conjunctivo dacryocystorhinostomy (CDCR) with Lester Jones tube. ${ }^{1}$ However, tuberelated complications (malposition, extrusion) and need for meticulous tube maintenance, may lead to patient dissatisfaction. ${ }^{2}$ Lester Jones tube has been avoided with some success in these challenging cases alternatively by retrograde intubation following dacryocystorhinostomy (DCR).

The authors report this surgical technique of anterograde fashioning of new lacrimal canaliculi with microvitreoretinal (MVR) blade and interposition of autogenous saphenous vein graft under endoscopic assistance for severe canalicular obstruction.

\section{CASE REPORT}

A 34-year male presented with complaint of persistent epiphora in his right eye for the last 4 years, associated with mild itching and discomfort. He had an external DCR one year back that failed to relieve his symptoms. There was no history of trauma, allergies or use of any topical medications. On ocular examination, a scar of previous external DCR was noted along the medial canthus with high tear film, patent punctum, mild mucoid discharge, and negative regurgitation test. Rest of his

Department of Ophthalmology, Armed Forces Institute of Ophthalmology (AFIO), Rawalpindi, Pakistan

Correspondence: Maj. Dr. Bushra Akbar, Department of Ophthalmology, Armed Forces Institute of Ophthalmology (AFIO), Rawalpindi, Pakistan

E-mail:dr.bushra.akbar@gmail.com

Received: August 07, 2018; Accepted: October 20, 2018 anterior and posterior segment examinations were unremarkable. Dye disappearance test with one drop of $2 \%$ fluorescein showed delayed clearance. Punctal probing was performed after punctal dilatation that revealed bi-canalicular obstruction $2 \mathrm{~mm}$ and $1 \mathrm{~mm}$ from superior and inferior puncti, respectively. Surgical reconstruction was carried out under general anaesthesia after obtaining an informed written consent. Autogenous saphenous vein graft tributary $(15 \mathrm{~cm})$ was harvested from the dorsum of right foot. Enlargement of previous osteotomy site and removal of fibrous membranes were done endoscopically. Superior and inferior canaliculi were anterogradely fashioned along their entire length with 23G MVR blade inserted through puncta; and optimal internal canalicular diameter was achieved via gentle and controlled backward side-toside movements. Prolene 2-0 suture was then passed through lumen of saphenous vein graft. Prolene mounted saphenous vein graft was then introduced through inferior punctum; and subsequently, through de novo generated canaliculus with MVR forceps and endoscopically retrieved through common canaliculus at the osteotomy site. Other end of graft was passed through same procedure for the superior canaliculus. Prolene 2-0 both ends, along with vein graft, were then tied in nasal cavity.

Postoperative visit at one week showed healthy graft tissue (Figure 1). Patency of canalicular pathways was confirmed on lacrimal dacryocystography at 3 months follow-up. Sac syringing at 3 and 6 months established free flow of fluid (Figure 2). Prolene 2-0 was removed endoscopically at 6 months. Functional improvement of epiphora was reported by the patient, and also objectively assessed as decreased tear film height with good cosmesis (Figure 3). 


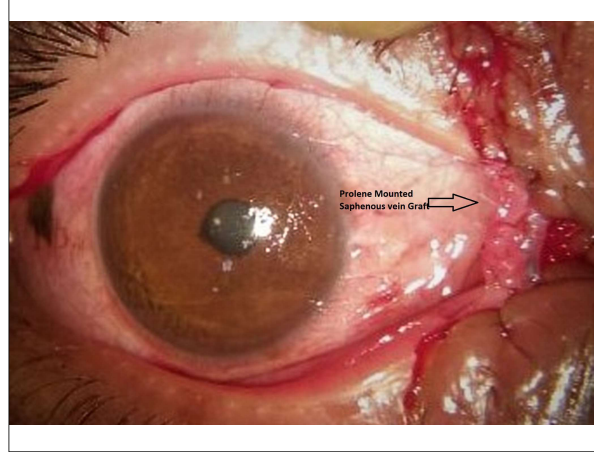

Figure 1: Prolene mounted saphenous vein graft 1 week follow-up.

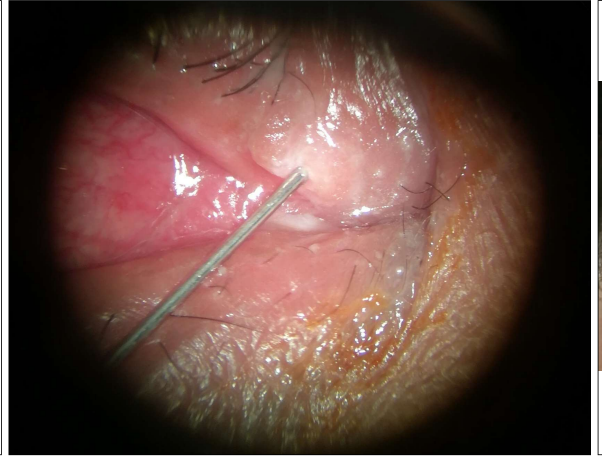

Figure 2: Punctal probing and sac syringing at 6 months post-op follow-up.

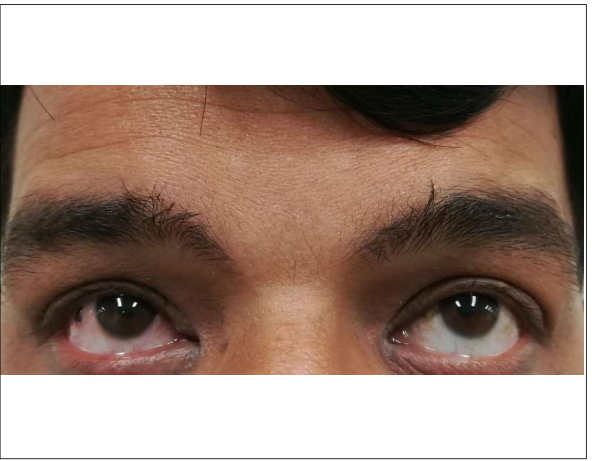

Figure 3: Functional success and cosmesis at 6 months follow-up.

\section{DISCUSSION}

Severe bi-canalicular obstruction is a challenging clinical scenario that has been alternatively managed by retrograde intubation as described by Wearne et al. and further modified by Trakos et al.3,4 This procedure principally incorporated external DCR, retrograde probing of canalicular system, generation of pseudo puncta, and silicon tubes intubation from one pseudopunctum to the other, before entering the nose in order to prevent trauma to the pseudopuncta. An innovation of anterograde creation of new canaliculi using MVR blade followed by microforceps-assisted canalicular insertion of Prolene mounted autogenous vein graft and endoscopic retrieval in nasal cavity. Prolene 2-0 allowed us anterograde easy insertion of graft without causing trauma to the newly constructed canaliculi, saving surgical time and yielded comparable functional results to prosthetic silicon tubes utilised in previous studies.3.4 Autogenous saphenous vein graft with various modifications has been safely used in lacrimal duct reconstruction and bypass surgery. CDCR with saphenous vein graft wrapped Lester Jones tube or transnasal creation of lacrimal lake bypass route, and subsequent interposition of vein graft as described by Tao et al. demonstrated effective long-term amelioration of epiphora.5,6 This surgical technique, aimed to restore the natural pathway of lacrimal drainage employing de novo creation of canaliculi with autogenous vein graft placement to provide scaffold and epithelialisation of reconstructed conduits, instead of using a trans- caruncular or lacrimal lake approach for interposition of graft and bypassing the lacrimal pathway.

To the best of the authors' knowledge, it is the first reported case of anterograde bi-canalicular reconstruction with autogenous saphenous vein graft rehabilitating the obstructed lacrimal canaliculi with functional success and good cosmesis. However, as this is a single case report, the authors intend to validate this conclusion with further larger case series and a randomised controlled trial with long-term follow up.

\section{REFERENCES}

1. Jones LT. Conjunctivodacryocystorhinostomy. Am J Ophthalmol 1965; 59:773-83.

2. Rosen N, Ashkenazi I, Rosner M. Patient dissatisfaction after functionally successful conjunctivodacryocystorhinostomy with Jones tube. Am J Ophthalmol 1994; 117:636-42.

3. Wearne MJ, Beigi B, Davis G, Rose GE. Retrograde intubation dacryocystorhinostomy for proximal and midcanalicular obstruction. Ophthalmology 1999; 106:2325-9.

4. Trakos N, Mavrikakis E, Boboridis KG, Ralidis M, Dimitriadis G, Mavrikakis I. A modified technique of retrograde intubation dacryocystorhinostomy for proximal canalicular obstruction. Clin Ophthalmol 2009; 3:681-4.

5. Tao H, Wu HY, Hou SK. Lacrimal duct reconstruction with grafting of great saphenous vein or labial mucosa via endoscopic transnasal dacryocystorhinostomy - A group comparison in 18 cases. J Clin Rehab Tissue Eng Res 2009; 13:8797-8800

6. Cohen AJ, Mercandetti M, Brazzo B. The lacrimal system; diagnosis. Management, and surgery. New York: Springer. 2006. 